\title{
Charcoal haemoperfusion and haemodialysis in acute intermittent porphyria
}

\author{
A C Y LAIWAH, B JUNOR, G J A MACPHEE, G G THOMPSON, K E L MCCOLL
}

\begin{abstract}
Charcoal haemoperfusion has been advocated as a means of removing $\delta$ aminolaevulinic acid, which accumulates in attacks of acute intermittent porphyria. A woman presented with acute intermittent porphyria unresponsive to conventional treatment and with pain that was difficult to control. Charcoal haemoperfusion was performed in series with haemodialysis for two hours daily on four consecutive days. Although during this treatment serum and urinary concentrations of $\delta$ aminolaevulinic acid and porphobilinogen were considerably reduced, they had returned to pretreatment values 24 hours after the end of treatment. Abdominal pain was not relieved.

Although a longer course of treatment might have had a more favourable outcome, this seems unlikely in view of the rapid rebound of serum concentration of $\delta$ aminolaevulinic acid after each haemoperfusion.
\end{abstract}

\section{Introduction}

Acute intermittent porphyria presents as severe attacks of abdominal pain, sometimes accompanied by neuropathy and mental disturbance, and may persist for months. It results from a hereditary partial block in the pathway of haem biosynthesis due to deficiency of uroporphobilinogen synthase. In clinical attacks there is an accumulation of the porphyrin precursors $\delta$ aminolaevulinic acid and porphobilinogen which are formed before the block, appear in the blood, and are excreted in the urine. The clinical manifestations have been explained on the basis of neurological dysfunction probably caused by the increased concentrations of circulating $\delta$ aminolaevulinic acid. Charcoal haemoperfusion has been advocated as a potential means of removing $\delta$ aminolaevulinic acid ${ }^{12}$; we report a trial of this treatment.

\section{Case report}

A 34 year old woman presented in 1974 with severe abdominal pain; she was taking the contraceptive pill. Increased urinary concentrations of $\delta$ aminolaevulinic acid and porphobilinogen confirmed the diagnosis of acute intermittent porphyria. After the contraceptive pill was stopped she continued to have recurrent episodes of abdominal pain lasting for up to a week. In 1981 after drinking some wine she developed a severe attack of porphyria with hypertension and peripheral motor neuropathy. Treatment with intravenous haematin produced little clinical benefit, and the attacks persisted for two months. Thereafter the attacks became more frequent and prolonged without any precipitating factors. Her most recent attack before this admission had continued for seven months, being unresponsive to

University Department of Medicine and Renal Unit, Western Infirmary, Glasgow G11 6NT

A C Y LAIWAH, MSC, MRCP, lecturer in medicine

B JUNOR, MD, MRCP, consultant renal physician

G J A MACPHEE, MRCP, registrar in medicine

G G THOMPSON, chief technician

K E L MCCOLL, MD, MRCP, lecturer in medicine

Correspondence to: Dr A C Y Laiwah, University Department of Medicine, Western Infirmary, Glasgow G11 6NT.

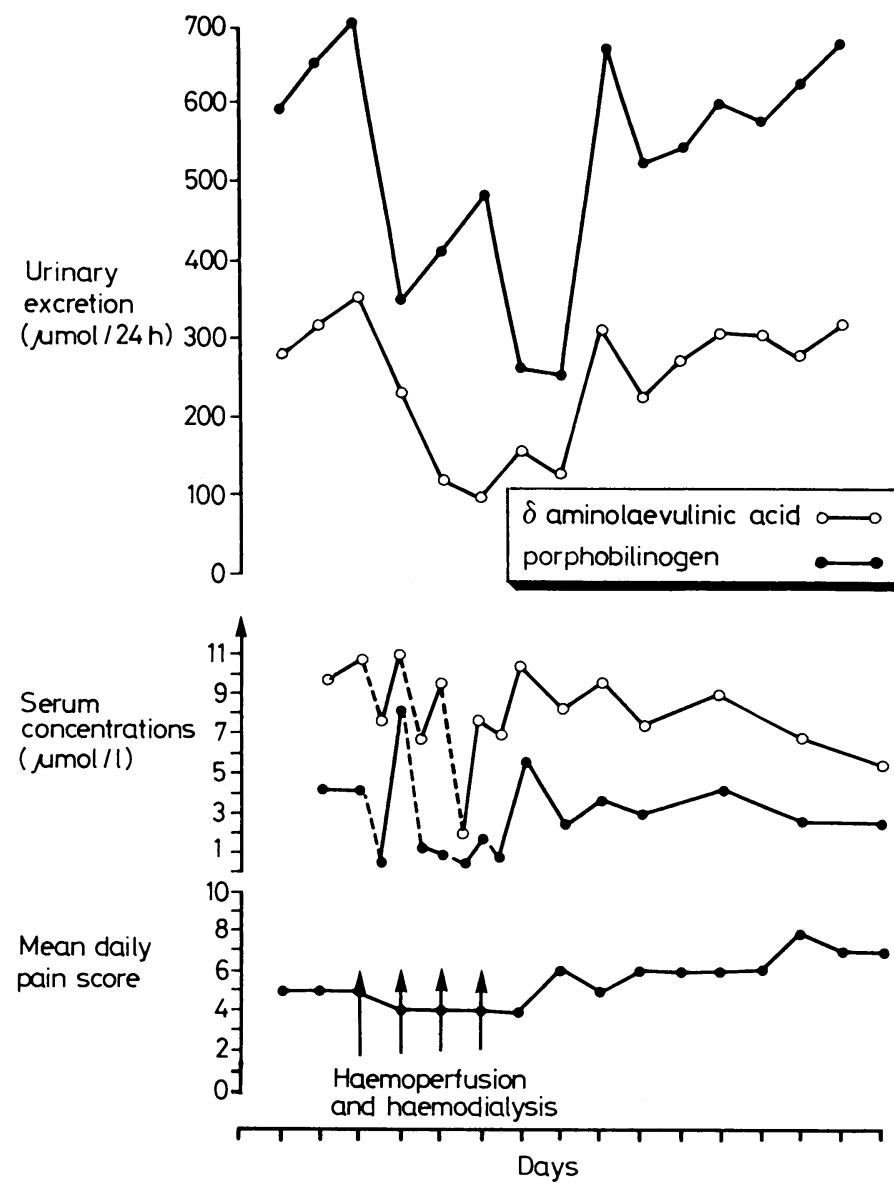

Sequential measurements of urinary and serum concentrations of $\delta$ aminolaevulinic acid and porphobilinogen in relation to mean daily pain score before a.ıd after four days of treatment with haemoperfusion and haemodialysis. Broken lines indicate concentrations immediately after perfusion.

Conversion: SI to traditional units $-\delta$ Aminolaevulinic acid: $1 \mu \mathrm{mol} \approx$ $121 \mu \mathrm{g}$. Porphobilinogen: $1 \mu \mathrm{mol} \approx 226 \mu \mathrm{g}$.

intensive conventional treatment and to high doses of propranolol and folic acid. ${ }^{3}$ Pain was difficult to control despite administration of large parenteral doses of narcotic analgesics.

After gaining written informed consent we performed haemoperfusion with a $300 \mathrm{~g}$ activated charcoal column (Adsorba 300; Gambro, Sweden) in series with haemodialysis for two hours daily on four consecutive days. The figure shows the effect of this treatment on mean daily pain scores (assessed on a visual analogue scale every four hours) and serum and urinary concentrations of $\delta$ aminolaevulinic acid and porphobilinogen. Haemoperfusion caused considerable thrombocytopenia, as previously reported. ${ }^{4}$ The platelet count, measured daily, fell from $204 \times 10^{9} / 1$ to $161 \times 10^{9} / 1$ after the first haemoperfusion and then steadily to $75 \times 10^{\circ} / 1$ after the fourth haemoperfusion, when treatment was stopped; but it had returned to normal by the seventh day after perfusion.

\section{Discussion}

The link between the biochemical disturbance of synthesis of haem and the pathogenesis of pain in acute intermittent porphyria has remained speculative. ${ }^{3} \mathrm{~A}$ strong association exists, 
however, between raised serum concentrations of $\delta$ aminolaevulinic acid and neurodysfunction. All four types of acute porphyria, in which concentrations of $\delta$ aminolaevulinic acid are raised, are characterised by neurological dysfunction whereas the non-acute porphyrias, which have normal concentrations of $\delta$ aminolaevulinic acid, are not. Furthermore, peripheral neuropathy is a feature of lead poisoning and hereditary tyrosinaemia, in which blood concentrations of $\delta$ aminolaevulinic acid are raised.

Intravenous infusion of haematin, which represses activity of $\delta$ aminolaevulinic acid synthase and hence lowers the increased blood concentrations of $\delta$ aminolaevulinic acid and porphobilinogen, provides some benefit in acute porphyria. ${ }^{5}$ Tishler et $a l^{12}$ reported that activated charcoal cartridges effectively removed large amounts of porphyrins and their precursors from solution in vitro, these amounts being considerably greater than estimated daily production during an attack of porphyria. The removal of $\delta$ aminolaevulinic acid and porphobilinogen and possibly other neurotoxic compounds by haemoperfusion through such sorbents might favourably alter the course of acute attacks.

In our study haemoperfusion with activated charcoal columns coupled with haemodialysis considerably reduced serum concentrations of $\delta$ aminolaevulinic acid and porphobilinogen with a concomitant decrease in urinary porphyrin precursors; but serum concentrations had returned to pretreatment values within 24 hours and abdominal pain was not relieved after four days' treatment. We cannot exclude the possibility that a longer course of treatment might have had a more favourable outcome, but this seems unlikely in view of the rapid rebound of serum concentrations of $\delta$ aminolaevulinic acid after each haemoperfusion. Furthermore, the resulting thrombocytopenia might present a major limiting factor to such treatment.

We thank Professor Sir Abraham Goldberg for his guidance.

\section{References}

1 Tishler PV, Gordon BJ, O'Connor JA. The absorption of porphyrins and porphyrin precursors by sorbents: a potential therapy for the porphyrias. Methods Find Exp Clin Pharmacol 1982;4:125-31.

2 Tishler PV, Gordon BJ. Sorbent therapy of the porphyrias. II. Experimental plasma or hemoperfusion with a commercial charcoal cartridge. Methods Find Exp Clin Pharmacol 1983;5:185-92.

3 Laiwah ACY, Goldberg A, Moore MR. Pathogenesis and treatment of acute intermittent porphyria: discussion paper. $\mathcal{f} R$ Soc Med 1983; 76:386-92.

4 Winchester JF, Ratcliffe JG, Carlyle E, Kennedy AC. Solute, amino acid, and hormone changes with coated charcoal hemoperfusion in uremia. Kidney Int 1978;14:74-81.

${ }^{5}$ McColl KEL, Moore MR, Thompson GG, Goldberg A. Treatment with haematin in acute hepatic porphyria. $Q \mathcal{F}$ Med 1981;50:161-74.

(Accepted 14 September 1983)

\title{
Complement activation during cardiopulmonary bypass: quantitative study of effects of methylprednisolone and pulsatile flow
}

\author{
MICHAEL J BOSCOE, VIRGINIA M A YEWDALL, MICHAEL A THOMPSON, \\ J STEWART CAMERON
}

\begin{abstract}
Forty four patients undergoing open heart surgery were divided into three groups. Group 1 (17 patients) underwent routine anaesthesia and surgery; group 2 (17 patients) received two doses of methylprednisolone (30 $\mathrm{mg} / \mathrm{kg}$ ), one during induction of anaesthesia and the other immediately before induction of cardiopulmonary bypass; and group 3 (10 patients) received pulsatile flow while undergoing pulsatile perfusion by the heart-lung machine. A modification of the previously described technique was used to detect and measure complement activation in plasma before and during the bypass period using crossed immunoelectrophoresis. About $45 \%$ of all patients showed measurable complement activation $(>4.5 \%)$ during cardiopulmonary by-
\end{abstract}

Department of Anaesthetics, Guy's Hospital, London SE1 9RT MICHAEL J BOSCOE, FFARCS, senior registrar MICHAEL A THOMPSON, MRCP, FFARCS, consultant

Department of Renal Medicine, Guy's Hospital Medical School, London

VIRGINIA M A YEWDALL, AIMLS, medical laboratory scientific officer J STEWART CAMERON, MD, FRCP, professor

Correspondence and requests for reprints to: $\operatorname{Dr} M \mathrm{~J}$ Boscoe. pass and the mean activation in this group was $6.4 \%$. There was no significant difference between the three groups in complement activation. In group 2, however, women showed significantly more complement activation than men $(\mathbf{p}<0.05)$.

It is suggested that neither corticosteroids nor pulsatile flow affect complement activation, but caution should be exercised in women receiving methylprednisolone.

\section{Introduction}

Cardiopulmonary bypass is thought to activate complement. ${ }^{12}$ The importance of this lies in the postoperative changes seen in lung function ${ }^{13}$ and possibly in changes in myocardial function. ${ }^{45}$ Attempts have been made to measure complement activation by changes in haemolytic activity $\left(\mathrm{CH}_{50}\right)^{2}{ }^{\circ} ?$ by aggregation of white cell polymorphs by activated complement components $^{8}$ and by measurement of absolute concentrations of complement. ${ }^{7}$ Complement activation has been measured in vivo by crossed immunoelectrophoresis for $\mathrm{C} 3 \mathrm{c}^{,}{ }^{10}$ by an assay for $\mathrm{C} 3 \mathrm{~d}$ using radial immunodiffusion, ${ }^{911}$ and by radioimmunoassay of $\mathrm{C} 3 \mathrm{a}$ and $\mathrm{C} 5 \mathrm{a} .{ }^{12}$ Earlier workers detected varying amounts of complement activation in the bypass period. Recent work has thrown doubt on these findings since an assay of $\mathrm{C} \mathrm{d}^{9}{ }^{11}$ failed to confirm complement activation in the bypass period. The use of either corticosteroid ${ }^{413}$ or pulsatile flow during cardiopulmonary bypass ${ }^{14} 15$ is controversial. 